\title{
Notes on the vocalizations of Giant Pitta (Pitta caerulea)
}

Peter Boesman

In the following we briefly analyze and compare voice of the two races of Giant Pitta (Pitta caerulea). We also try to quantify the extent of any vocal differences using the criteria proposed by Tobias et al. (2010), as a support for taxonomic review. We have made use of sound recordings available on-line from Xeno Canto (XC) and Macaulay Library (ML).

Examples from Borneo (hosei)

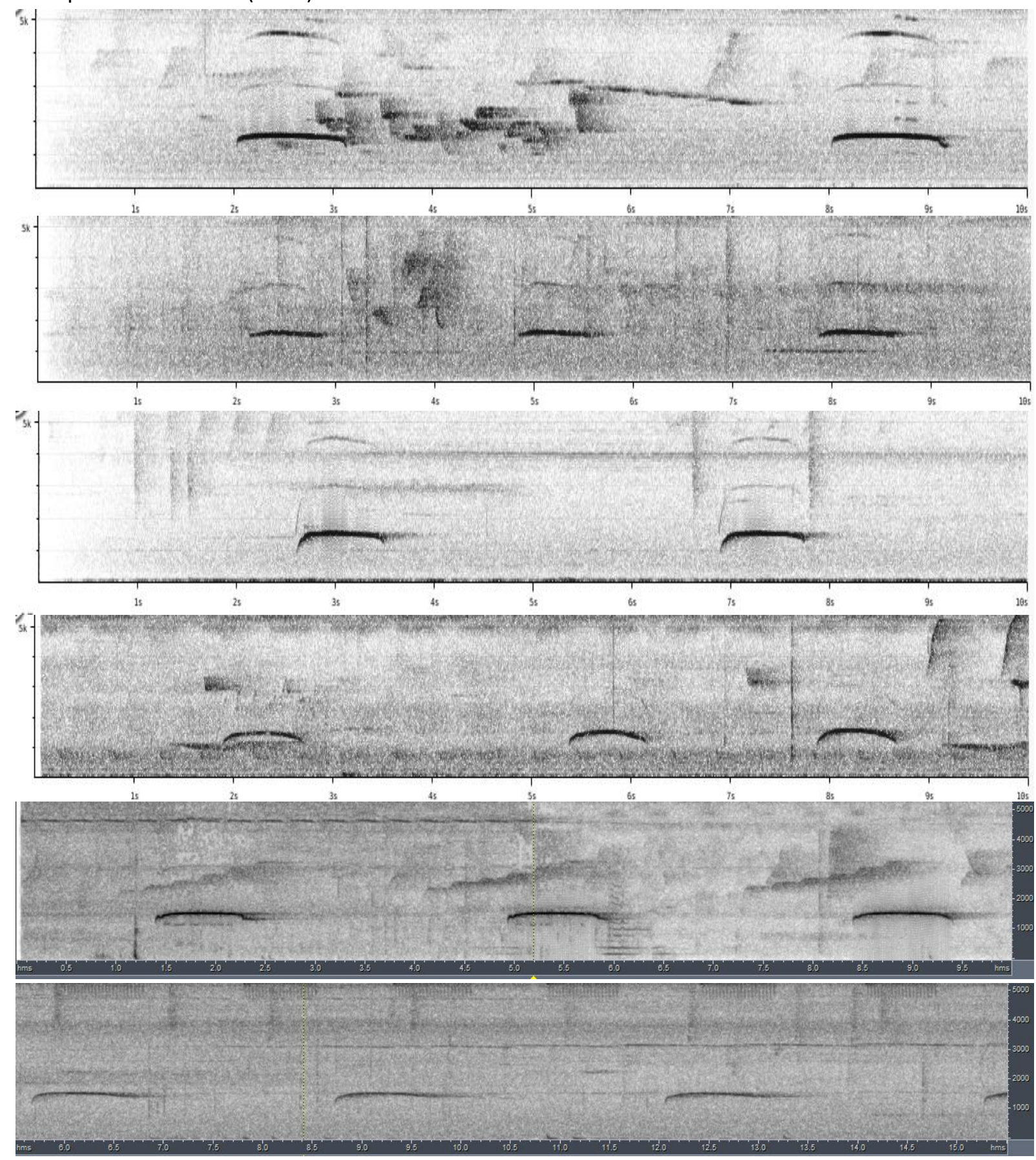



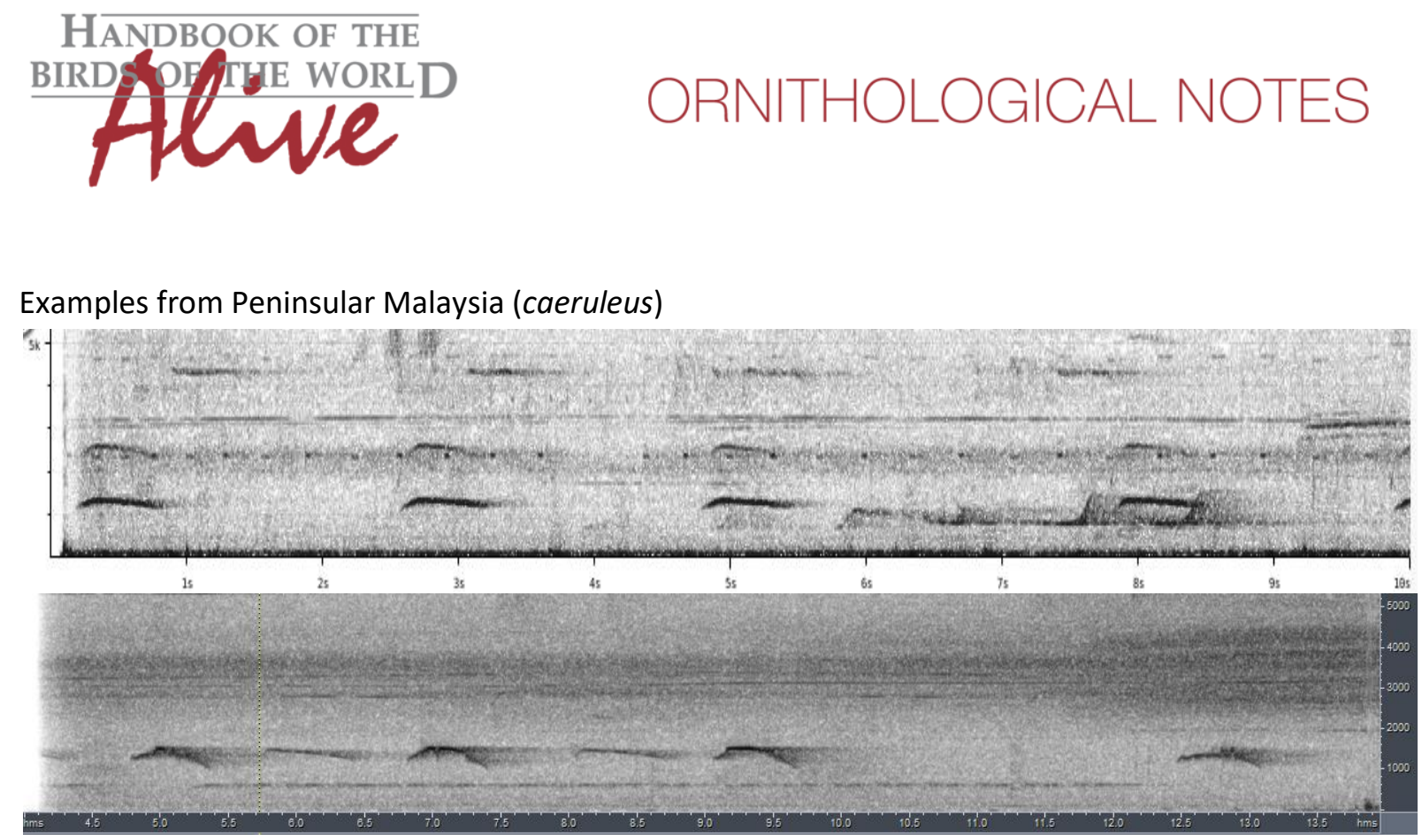

There are only a few recordings available from Peninsular Malaysia. These birds (caeruleus) seem to utter a much shorter whistle, which results in a quite different sound to the ear (more subdued, less drawn-out and haunting as in hosei).

Whistle length:

hosei: $\quad 0.78-1.18 \mathrm{~s}$

caerulea: $\quad 0.58-0.66 \mathrm{~s}$

When applying Tobias criteria, this would lead to a total vocal score of 2 based on whistle length.

This note was finalized on 20th June 2016, using sound recordings available on-line at that moment. We would like to thank in particular the sound recordists who placed their recordings for this species on XC and ML: Pritam Baruah, Tomas Carlberg, David Edwards, Yong Ding Li, Linda Macaulay and Mike Nelson.

\section{References}

Tobias, J.A., Seddon, N., Spottiswoode, C.N., Pilgrim, J.D., Fishpool, L.D.C. \& Collar, N.J. (2010). Quantitative criteria for species delimitation. Ibis 152(4): 724-746.

\section{Recommended citation}

Boesman, P. (2016). Notes on the vocalizations of Giant Pitta (Pitta caerulea). HBW Alive Ornithological Note 257. In: Handbook of the Birds of the World Alive. Lynx Edicions, Barcelona. (retrieved from http://www.hbw.com/node/1245102 on 4 October 2016). 